\title{
A comparison of the superficial inferior epigastric artery flap and deep inferior epigastric perforator flap in postmastectomy reconstruction: A cost-effectiveness analysis
}

\author{
Achilleas Thoma MD MSc FRCSC FACS ${ }^{1,2,3}$, Leigh Jansen BSc FSA ${ }^{4}$, Sheila Sprague MSc ${ }^{3}$, Eric Duku MSc P.Stat ${ }^{5}$
}

\begin{abstract}
A Thoma, L Jansen, S Sprague, E Duku. A comparison of the superficial inferior epigastric artery flap and deep inferior epigastric perforator flap in postmastectomy reconstruction: A cost-effectiveness analysis. Can J Plast Surg 2008;16(2):77-84.
\end{abstract}

PURPOSE: To perform a cost-effectiveness analysis comparing the superficial inferior epigastric artery (SIEA) and deep inferior epigastric perforator (DIEP) flaps in postmastectomy reconstruction.

METHODS: A decision analytic model with seven clinically important health outcomes (health states) was used, incorporating the Ontario Ministry of Health's perspective. Direct medical costs were estimated from a university-based hospital. The utilities of each health state converted into quality-adjusted life years (QALYs) were obtained from previously published data. Health state probabilities were computed from a systematic literature review. Analyses yielded SIEA and DIEP expected costs and QALYs allowing calculation of the incremental cost-utility ratio (ICUR). One-way sensitivity analyses were conducted under five plausible scenarios, assessing result robustness.

RESULTS: Five SIEA and 27 DIEP studies were identified. The baseline SIEA expected cost was slightly higher than that for the $\operatorname{DIEP}(\$ 16,107$ versus $\$ 16,095)$, with slightly higher QALYs (33.14 years versus 32.98 years), giving an ICUR of \$77/QALY. Taking into account conversions from SIEA to DIEP, the ICUR increased to $\$ 4,480 /$ Q ALY. Sensitivity analysis gave ICURs ranging from $\$ 2,614 /$ QALY to 'dominant', all consistent with the adoption of the SIEA over the DIEP.

CONCLUSION: The best available evidence suggests the SIEA is a cost-effective procedure. However, given the high SIEA to DIEP conversion rates and small marginal differences in cost and effectiveness, the ICUR may be sensitive to minor changes in costs or QALYs. The 'truth' can only be obtained from a randomized, controlled trial comparing both techniques side by side, simultaneously capturing the costs of the competing interventions.

Key Words: Breast reconstruction; Cost-effectiveness; Cost-utility analysis; Quality-adjusted life years; Postmastectomy
Une comparaison entre le lambeau de l'artère épigastrique inférieure superficielle et le lambeau perforant de l'artère épigastrique inférieure profonde dans le cadre d'une reconstruction après une mastectomie : Une analyse coût-efficacité

\begin{abstract}
OBJECTIF : Effectuer une analyse coût-efficacité comparant un lambeau de l'artère épigastrique inférieure superficielle (SIEA) à un lambeau perforant de l'artère épigastrique inférieure profonde (DIEP) pour la reconstruction après une mastectomie.

MÉTHODOLOGIE : Les auteurs ont utilisé un modèle d'analyse décisionnelle comportant sept issues de santé importantes d'un point de vue clinique (états de santé), incluant la perspective du ministère de la Santé de l'Ontario. Ils ont estimé les coûts médicaux directs d'après un hôpital universitaire. Ils ont obtenu l'utilité de chaque état de santé converti en années de vie pondérées par la qualité (AVPQ) dans des données déjà publiées. Ils ont calculé les probabilités relatives aux états de santé au moyen d'une analyse bibliographique systématique. Les analyses ont fourni les coûts prévus des SIEA et des DIEP ainsi que de l'AVPQ et ont ainsi permis le calcul du ratio coût-utilité incrémentiel (RCUI). Ils ont procédé à des analyses de sensibilité unidirectionnelles en vertu de cinq scénarios plausibles, afin d'évaluer la solidité des résultats.

RÉSULTATS : Les auteurs ont repéré cinq SIEA, 27 DIEP et des études. Le coût prévu de base du SIEA était légèrement plus élevé que celui du DIEP (16 107 \$ par rapport à 16095 \$) et s'associait à des AVPQ légèrement plus positives (33,14 ans par rapport à 32,98 ans), pour un RCUI de 77 \$AVPQ. Compte tenu de la conversion du SIEA au DIEP, le RCUI augmentait à 4480 \$/AVPQ. L'analyse de sensibilité a donné des RCUI variant entre 2614 \$/AVPQ et « dominant », en harmonie avec l'adoption du SIEA plutôt que du DIEP.

CONCLUSION : Les meilleures données disponibles indiquent que le SIEA est une intervention rentable. Cependant, étant donné les taux de conversion élevés de SIEA à DIEP et les petites différences marginales du point de vue du coût et de l'efficacité, le RCUI est peut-être sensible à des modifications mineures des coûts ou de l'AVPQ. On obtiendra la « vérité » seulement à partir d'un essai aléatoire et contrôlé comparant conjointement les deux techniques afin de saisir simultanément le coût de ces interventions concurrentielles.
\end{abstract}

\footnotetext{
${ }^{1}$ Department of Surgery, Division of Plastic and Reconstructive Surgery, St Joseph's Healthcare; ${ }^{2}$ Surgical Outcomes Research Centre (SOURCE), McMaster University; ${ }^{3}$ Department of Clinical Epidemiology and Biostatistics, McMaster University; ${ }^{4}$ Michael G DeGroote School of Medicine, McMaster University; ${ }^{5}$ Department of Psychiatry and Behavioural Neurosciences, McMaster University, Hamilton, Ontario Correspondence: Dr Achilleas Thoma, 206 James Street South, Suite 101, Hamilton, Ontario L8P 3A9. Telephone 905-523-0019,

fax 905-523-0229, e-mail athoma@mcmaster.ca
} 
Ther here are many postmastectomy reconstructive options. Some procedures such as tissue expanders and implants (1$3)$, and the transverse rectus abdominis myocutaneous (TRAM) flap (4-6), have been used for many years, whereas others such as the deep inferior epigastric perforator (DIEP) flap (6-8), muscle-sparing TRAM flaps (9) and the superficial inferior epigastric artery (SIEA) flap are relatively new. In the quest for the best abdominal autogenous tissue reconstruction technique, there has been a recent trend to minimize the harvesting of the rectus abdominis muscle and its fascia.

The evidence so far supports the transition toward those techniques that reduce anatomical disruption to the abdomen. Therefore, there is a need to question why the SIEA flap, which leaves the rectus muscle and anterior rectus fascia intact, has not been widely accepted $(6,10,11)$. Taylor and Daniel (10) described the SIEA flap anatomy in 1975, but it was only in the 1990s that case series first reported its use for breast reconstruction (11). Subsequent reports have emphasized that the SIEA vessel length and diameter are both shorter and smaller, respectively, than in the TRAM or DIEP flaps $(12,13)$. The SIEA and superficial inferior epigastric vein are not present as single dominant flap vessels in $35 \%$ of dissections. The pedicle is short and the SIEA's external diameter is very small $(0.8 \mathrm{~mm}$ to $2.5 \mathrm{~mm})$, with an average of $1.4 \mathrm{~mm}(13,14)$. The DIEP flap also spares the rectus abdominis muscle and fascia, but it relies upon the deep inferior epigastric vessels, requiring a fascial incision, suggesting higher abdominal complications than the SIEA (15). The DIEP has been generally accepted because it has a longer pedicle and has an arterial external diameter of $3.4 \mathrm{~mm}$ at its origin $(14,16)$.

A comparison of the muscle-sparing free TRAM flap with the DIEP found that there were no statistically significant differences in outcomes, but costs were not included in this analysis (9). However, previous cost-effectiveness studies $(17,18)$ found that the introduction of techniques that caused less disruption of muscle and fascia were cost-effective in the Canadian health care system.

Recent articles comparing the SIEA and DIEP flaps have been published $(6,19)$, but none employs a full economic analysis. In an economic analysis comparing any two surgical techniques, there are nine possible outcomes based on incremental cost and effectiveness of a given procedure over another (Figure 1) (20). Some decisions are clear-cut - for instance, cell 1 represents the case where the novel procedure is both less expensive and more effective than the traditional technique, a 'win-win' situation. Similarly, if a procedure falls into cell 2, where it is more expensive and less effective, it should be rejected. Many decisions, however, are not as straightforward. Most new surgical procedures fall into cell 7; they are more effective, but also more expensive. In such cases, given the constraints of limited health care resources, economic analyses can facilitate decision making (21).

There are many different types of economic analyses (22), but all share the principle of weighing both costs and benefits. A cost-utility analysis, which is a variant of cost-effectiveness analysis, permits comparisons across programs and interventions, as it uses a common 'metric' for measuring outcomes, the quality-adjusted life year (QALY). In a cost-utility analysis, one determines the utilities, or preferences, associated with the outcomes of different procedures. By quantifying these utility values, and applying them to a patient's remaining lifetime, an

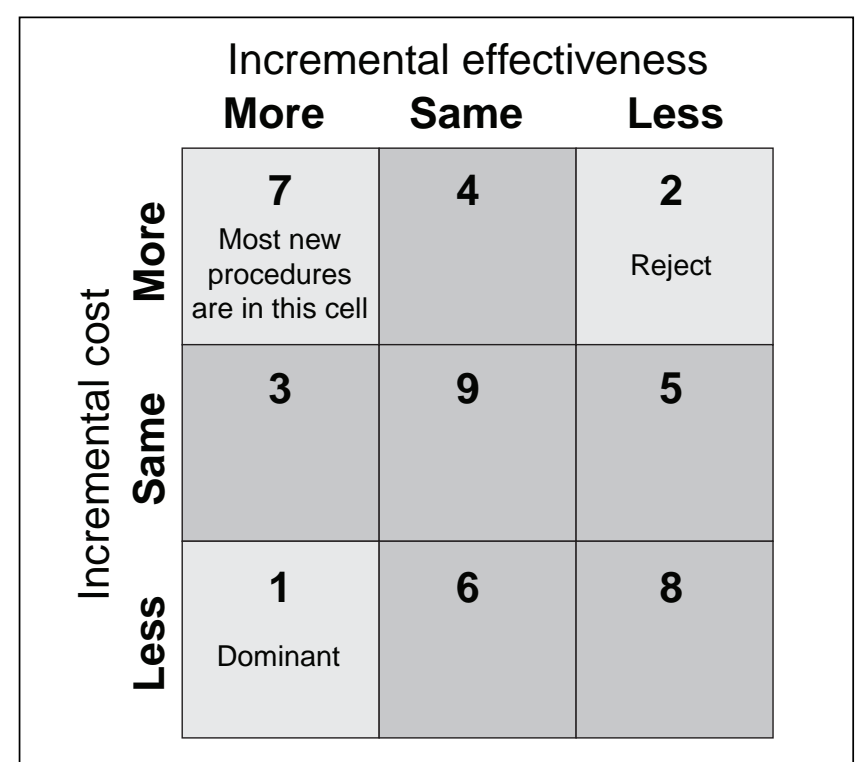

Figure 1) Comparison of cost and effectiveness. Adapted from reference 20

expected number of future healthy years of life can be calculated and weighed against associated costs.

The purpose of the present study was to perform a cost-utility analysis comparing surgical techniques involving the SIEA and DIEP flaps, to assist surgeons in selecting a cost-effective approach to postmastectomy reconstruction.

\section{METHODS}

The necessary steps in performing a cost-utility analysis using a decision analytic model are as follows:

- identifying the relevant perspective;

- identifying the clinically important outcomes or 'health states' (effectiveness) associated with the interventions under consideration;

- identifying accurate and relevant costs associated with the competing techniques;

- calculating the incremental cost-utility ratio (ICUR); and

- performing sensitivity analysis to assess the robustness of the baseline calculations.

Various perspectives can be taken when conducting economic analyses, such as the perspective of the patient, hospital, primary payer or society (20). In the present study, the perspective of the primary payer of Ontario (the Ontario Ministry of Health) was considered to be relevent.. Ontario is the most populous province in Canada, and these costs can be easily and accurately obtained. Because indirect costs were unavailable, the societal perspective would be inappropriate in this deterministic analysis (a deterministic analysis is based on fixed probabilities, derived from pooled secondary data).

\section{Health outcomes probabilities}

In a cost-utility analysis, one must consider the spectrum of possible outcomes. For the purpose of the present study, seven mutually exclusive clinically significant health outcome states were considered: total flap failure, partial flap failure, 
fat necrosis, hernia, hematoma, abdominal wall weakness and successful surgery (18).

A systematic literature review was undertaken. The following electronic databases were searched to locate all SIEA and DIEP studies: MEDLINE, EMBASE and Cochrane. Articles were limited to those in English, based on humans, and from 1991 to May 2006. The following keywords were used: "DIEP" or "deep inferior epigastric perforator flap" or "deep inferior epigastric perforator" or "SIEA" or "superficial inferior epigastric artery flap" or "free TRAM" or "muscle sparing TRAM" or "pedicled TRAM", combined with "breast reconstruction" or "postmastectomy reconstruction". Single case reports and review articles were excluded.

The article selection was conducted by two independent assessors (LJ, SS) to avoid selection bias, with results compared and reconciled at each stage. Interassessor agreements were compared using the Kappa statistic. A third assessor (AT) acted as arbitrator, as required, to resolve uncertainty as to whether an article was relevant.

It was necessary to consider an added dimension of complexity for the SIEA flap: the conversion rate to another flap type due to the unpredictability of the SIEA vascular anatomy. Different results could be obtained depending on whether outcomes are considered based on attempted SIEA flaps or completed SIEA flaps. As mentioned in the introduction, the SIEA and superficial inferior epigastric vein are not present as single dominant flap vessels in 35\% of dissections (14). Even when preoperative colour Doppler ultrasounds are used to localize, measure and identify the SIEA flap vascular supply, the SIEA is often deemed to be unsuitable based on the intraoperative assessment $(23,24)$. Two approaches to deal with this uncertainty were considered. In the first, coined the efficacy analysis, it was assumed that if the SIEA is attempted, it is completed as intended - in other words, the issue of SIEA conversions was ignored. In the second, coined the effectiveness analysis, the reality that a certain percentage of attempted SIEA flaps would be switched to a different type of reconstructive flap was taken into consideration. It was assumed that the operative time for these 'conversions' would be increased by $30 \mathrm{~min}$, and that a DIEP would be performed as the alternative procedure.

The following data were extracted from the selected articles: number of patients, number of flaps, SIEA to DIEP conversion rates, types and rates of postoperative complications, operating room time and number of postoperative hospital days.

Based on the data listed above, the following metrics were computed: probabilities for each health outcome state, SIEA to DIEP conversion rate, average operating room time and average postoperative hospital days.

When extracting data, a distinction was made between zeros and nulls, so that numerators and denominators could be adjusted appropriately when calculating probabilities. For example, many studies did not report whether there were any cases of abdominal wall weakness. In the present calculations, these studies were excluded from the counts in the denominators to avoid underestimating their probabilities of occurrence.

All calculations were performed using Microsoft Excel Office 2003 (Microsoft Inc, USA).

\section{Costs}

Direct costs based on the Schedule of Benefits: Physician Services Under the Health Insurance Act (25) were considered, as well as 2006 hospital costs for the operating room and minor procedures room from the budgeting services department for $\mathrm{St}$ Joseph's Healthcare, a McMaster University (Hamilton, Ontario) teaching hospital. The costs for tissue expanders and permanent silicone breast implants were estimated based on figures supplied by Mentor Canada in October 2006.

The associated cost was determined for each health outcome. For example, under the total flap failure scenario, it was assumed that the patient would return to the operating room for debridement and the insertion of a tissue expander followed by permanent implant. Under the hernia scenario, it was assumed that the patient would return to the operating room for a hernia repair. The assumption was made that under the abdominal wall weakness scenario, no surgery would be necessary. The expected cost for each health outcome (health state) is calculated as the probability-weighted cost associated with each potential outcome.

\section{Effectiveness}

QALYs are calculated based on two key inputs: the utilities (preferences) for the potential outcomes, and the period of time over which the utilities apply. Utilities that were obtained from a survey of 32 plastic surgeons across Canada in 2004 were used (18). These utilities were obtained using a generic scale based on the 'feeling thermometer' visual analogue, where 0 represents death and 1 represents perfect health (26). For example, the utility for the hernia health state was obtained by calculating the mean score assigned to the following scenario: "You underwent a deep inferior epigastric perforator flap and have developed an abdominal hernia that requires operative repair". The duration of the health state in this case was 16 weeks.

Based on the utility values and health state duration, QALYs were calculated according to the following formula:

$$
\begin{gathered}
\text { QALY }=(\text { duration of health state }) \times(\text { utility of health } \\
\text { state })+(\text { future remaining lifetime after health state }) \times \\
(\text { utility of successful reconstruction health state })
\end{gathered}
$$

\section{ICUR}

The ICUR, which represents the marginal cost per marginal unit of utility, was calculated as follows:

$$
\begin{aligned}
& \text { ICUR }=\Delta \mathrm{C} / \Delta \mathrm{U}=\left({\text { Mean } \text { Cost }_{\text {SIEA }}-\text { Mean Cost }}_{\text {DIEP }}\right) / \\
& \text { (Mean } \text { QALY }_{\text {SIEA }} \text { - Mean QALY DIEP) }
\end{aligned}
$$

The result is represented as cost per QALY. In simple words, it tells us how much it costs to prolong the life of a patient by one extra year in perfect health. The higher the ICUR, the greater the incremental cost for an additional healthy year of life. It is generally accepted that if an intervention has an ICUR below the threshold of $\$ 20,000 / Q A L Y$, there is a strong indication for its acceptance. On the other hand, if the ICUR is above the threshold of $\$ 100,000 / Q A L Y$, there is an indication for its rejection (27).

\section{Sensitivity analysis}

One-way sensitivity analyses were conducted under five plausible scenarios to assess the result robustness. In each scenario, it was assumed that specific model parameters were the same for both the SIEA and DIEP. The scenarios tested 


\section{TABLE 1}

Data for superficial inferior epigastric artery flaps

\begin{tabular}{|c|c|c|c|c|c|c|c|c|c|c|c|}
\hline $\begin{array}{l}\text { Reference (first } \\
\text { author, year) }\end{array}$ & $\begin{array}{c}\text { Total } \\
\text { patients }\end{array}$ & $\begin{array}{l}\text { Total } \\
\text { flaps }\end{array}$ & Success & Hernia & $\begin{array}{c}\text { Abdominal } \\
\text { wall weakness }\end{array}$ & Hematoma & $\begin{array}{l}\text { Total flap } \\
\text { failure }\end{array}$ & $\begin{array}{c}\text { Partial } \\
\text { flap loss }\end{array}$ & $\begin{array}{c}\text { Fat } \\
\text { necrosis }\end{array}$ & $\begin{array}{c}\text { OR time, } \\
h\end{array}$ & $\begin{array}{c}\text { Hospital } \\
\text { days }\end{array}$ \\
\hline Chevray, 2004 (6) & 12 & 14 & 9 & 0 & 0 & 0 & 1 & 0 & 2 & NR & $N R$ \\
\hline Vega, 2006 (30) & 10 & 20 & 10 & 0 & $N R$ & 0 & 0 & 0 & 0 & 7.9 & 8.9 \\
\hline $\begin{array}{l}\text { Vermeulen, } \\
2005 \text { (28) }\end{array}$ & 42 & 43 & 32 & & $N R$ & 1 & 2 & 1 & 6 & NR & 4.7 \\
\hline Denominator & & & 76 & 22 & 12 & 76 & 222 & 89 & 77 & 3.0 & 3.0 \\
\hline Probability/Average & & & 0.8158 & 0.0000 & 0.0000 & 0.0132 & 0.0180 & 0.0225 & 0.1039 & 7.1 & 5.9 \\
\hline
\end{tabular}

Rates for successful surgeries, hernia, abdominal wall weakness, and hematoma based on number of patients. Rates for total flap failure, partial flap loss, and fat necrosis based on number of flaps. NR Not reported; OR Operating room

included: operating room time, postoperative days in hospital, hernia rate, total flap failure rate and rate of abdominal wall weakness.

\section{RESULTS}

\section{Health outcome probabilities}

The initial literature search yielded 272 possibly relevant articles. After the reviewer screen, 115 articles remained, with good inter-reviewer agreement $($ Kappa $=0.87)$. Their abstracts were reviewed, resulting in the retention of 45 articles, also with good agreement $($ Kappa $=0.79)$. Finally, the full text review of these remaining 45 articles resulted in the retention of 26 articles from which data were extracted.

Three SIEA articles were identified describing results for 46 flaps and 34 patients. Given the paucity of SIEA data, the analysis was supplemented with data from two abstracts published at recent American Society for Reconstructive Microsurgery meetings $(28,29)$. Two SIEA articles that were found after the initial search were also included $(19,30)$. In summary, a total of 30 studies were used for the present analysis (five SIEA [Table 1] [6,19,28-30]) and 27 DIEP [Table 2] [6,9,13,28,31-53].

The probability of successful reconstruction was approximately $80 \%$ for both the SIEA (0.8158) and the DIEP $(0.7843)$. Given that the sum of all probabilities of outcomes must sum to $100 \%$ (including successful reconstruction and all complications), the probabilities for the six health states with complications were adjusted to accommodate the rounding of success to $80 \%$ (Table 3 ).

\section{Costs}

The average operating room times for the SIEA and DIEP were $7.1 \mathrm{~h}$ and $6.7 \mathrm{~h}$, respectively. The average postoperative hospital days for the SIEA and DIEP were 5.9 days and 6.3 days, respectively (Tables 1 and 2 ).

The SIEA to DIEP conversion rate was estimated to be $60 \%$, based on experience with 200 SIEA flap cases (24).

The baseline costs and incremental costs associated with each outcome are shown in Table 4. These costs are used to calculate expected costs for the DIEP and SIEA, based on the probabilities of the various complications. The direct costs for the SIEA and DIEP are similar $(\$ 15,968$ and $\$ 15,998$, respectively), and the additional costs range from $\$ 5,043$ for total flap failure, to zero, for abdominal wall weakness where no action is taken.
The probabilities, costs and expected costs under the SIEA and DIEP models are shown in Figures 2 and 3, respectively.

\section{Effectiveness}

The seven health states and their associated utilities, duration, and QALYs are presented in Table 5. A successful reconstruction had a highest utility of 0.87 , while the utility for total flap failure is 0.61 . Health state durations were computed for a woman currently aged 45 years, with an expected life expectancy of 83.36 years (ie, a future remaining life expectancy of 38.36 years) (54).

QALYs are calculated according to the following formula:

QALY $=$ (duration of health state) $\times$ (utility of health state) + (future remaining life expectancy - duration of

health state) $\times$ (utility of successful reconstruction)

For example, the fat necrosis outcome has a utility of 0.74 with a state duration of 0.25 years. The utility for a successful reconstruction is 0.87 . Therefore, the QALY for this state is:

$$
0.25 \times 0.74+(38.36-0.25) \times 0.87=33.34 .
$$

\section{ICUR}

Based on these results, the efficacy model ICUR can be calculated as follows:

$$
\begin{gathered}
\text { Efficacy model ICUR }=\left[\left(\text { Expected Cost }_{\text {SIEA }}-(\text { Expected }\right.\right. \\
\left.{\text { Cost } \left.)_{\text {DIEP }}\right] /[\text { Expected QALY }}_{\text {SIEA }}-\text { Expected QALY }_{\text {DIEP }}\right]= \\
\begin{array}{r}
\$ 16,107-\$ 16,095) /(33.14 \text { QALYS }-32.98 \text { QALYS })= \\
\$ 77.40 / \text { QALY }
\end{array} \\
\text { (intermediate calculations, rounded off })
\end{gathered}
$$

As mentioned earlier, the efficacy model ignores SIEA conversions. The effectiveness model ICUR calculation is slightly more complex (Figure 4). The SIEA is more expensive by $\$ 284$ and more effective by 0.06 QALYs, implying an ICUR of $\$ 4,480 / Q A L Y$. Figure 5 displays the efficacy and effectiveness results on the cost-effectiveness plane.

\section{Sensitivity analysis}

One-way sensitivity analyses under the efficacy model were performed under five plausible scenarios. When the postoperative days for the SIEA were changed from 5.9 days to 6.3 days (the DIEP value), the ICUR was $\$ 2,614 /$ QALY. When the 
TABLE 2

Data for deep inferior epigastric perforator flaps

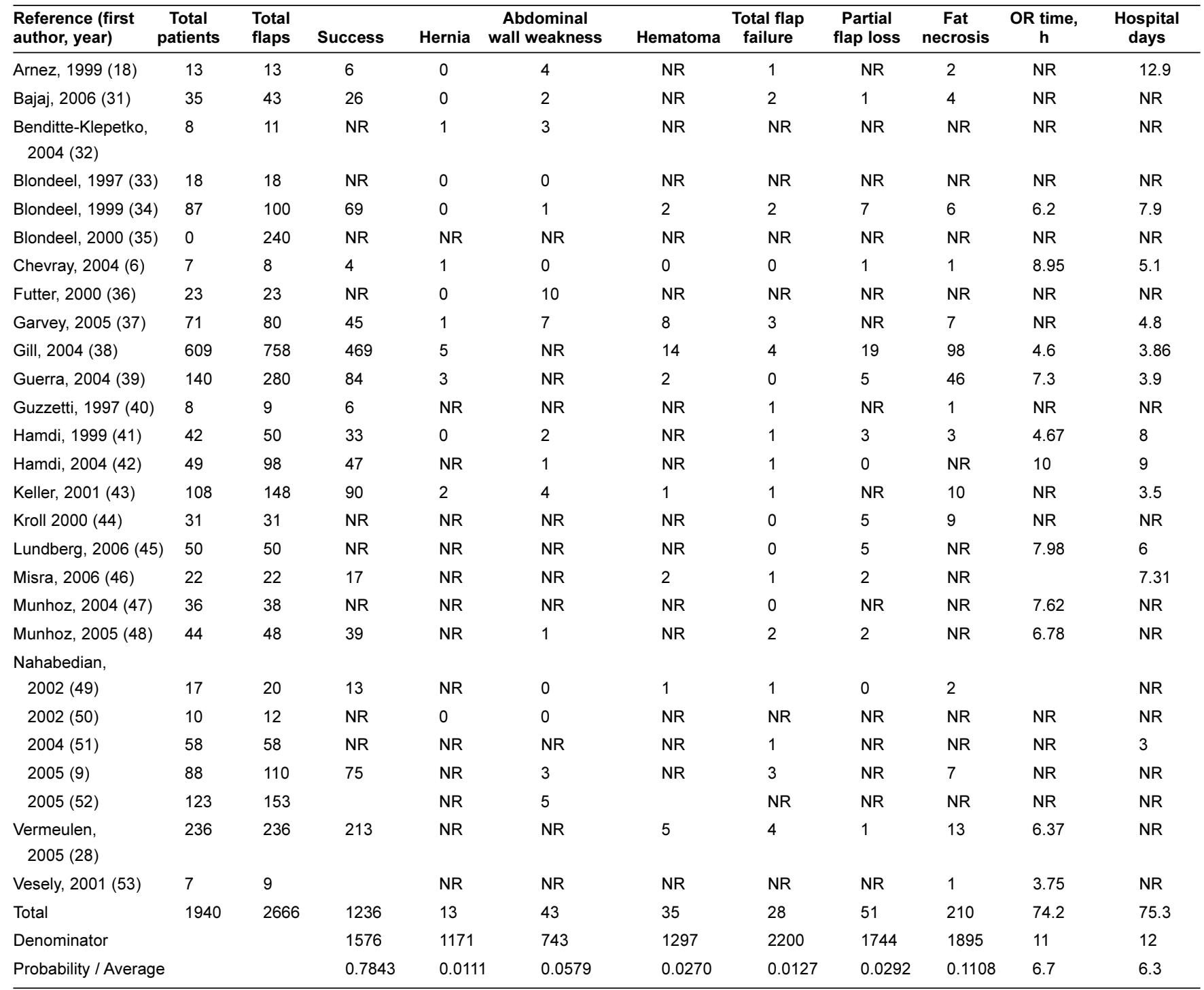

Rates for successful surgeries, hernia, abdominal wall weakness, and hematoma based on number of patients. Rates for total flap failure, partial flap loss, and fat necrosis based on number of flaps.NR Not reported; OR Operating room

TABLE 3

Probability adjustments

\begin{tabular}{|c|c|c|c|c|c|c|}
\hline \multirow[b]{2}{*}{ Outcome } & \multicolumn{2}{|c|}{ Raw } & \multicolumn{2}{|c|}{ Adjusted to $\mathbf{2 0} \%$} & \multicolumn{2}{|c|}{ Adjusted to $100 \%$} \\
\hline & SIEA & DIEP & SIEA & DIEP & SIEA & $\overline{\text { DIEP }}$ \\
\hline $\begin{array}{c}\text { Total flap } \\
\text { failure }\end{array}$ & 0.0180 & 0.0127 & 0.0229 & 0.0102 & 0.1144 & 0.0512 \\
\hline Hernia & 0.0000 & 0.0111 & 0.0000 & 0.0089 & 0.0000 & 0.0446 \\
\hline $\begin{array}{l}\text { Abdominal } \\
\text { wall } \\
\text { weakness }\end{array}$ & 0.0000 & 0.0579 & 0.0000 & 0.0465 & 0.0000 & 0.2327 \\
\hline $\begin{array}{l}\text { Partial flap } \\
\text { loss }\end{array}$ & 0.0225 & 0.0292 & 0.0285 & 0.0235 & 0.1426 & 0.1176 \\
\hline Fat necrosis & 0.1039 & 0.1108 & 0.1319 & 0.0891 & 0.6595 & 0.4455 \\
\hline Hematoma & 0.0132 & 0.0270 & 0.0167 & 0.0217 & 0.0835 & 0.1085 \\
\hline Total & 0.1575 & 0.2487 & 0.2000 & 0.2000 & 1.0000 & 1.0000 \\
\hline
\end{tabular}

Adjusted probabilities calculated after rounding probability of success to $80 \%$. DIEP Deep inferior epigastric perforator flap; SIEA Superficial inferior epigastric artery flap
TABLE 4

Baseline and incremental costs*

\begin{tabular}{|c|c|c|c|c|c|}
\hline & $\begin{array}{c}\text { Physican } \\
\text { fees, \$ }\end{array}$ & $\begin{array}{l}\text { Anesthetist } \\
\text { fees, } \$\end{array}$ & $\begin{array}{l}\text { Hospital } \\
\text { costs, \$ }\end{array}$ & $\underset{\$}{\text { Materials, }}$ & $\begin{array}{l}\text { Total direct } \\
\text { costs, } \$\end{array}$ \\
\hline SIEA & $2,339.00$ & 738.00 & $12,890.00$ & 0.00 & $15,968.00$ \\
\hline DIEP & $2,298.00$ & 701.00 & $12,999.00$ & 0.00 & $15,998.00$ \\
\hline $\begin{array}{l}\text { Total flap } \\
\text { failure }\end{array}$ & 634.00 & 175.00 & $2,009.00$ & $2,225.00$ & $5,043.00$ \\
\hline $\begin{array}{l}\text { Partial flap } \\
\text { failure }\end{array}$ & 37.00 & 0.00 & 97.00 & 0.00 & 134.00 \\
\hline Fat necrosis & 37.00 & 0.00 & 97.00 & 0.00 & 134.00 \\
\hline Hernia & 371.00 & 150.00 & $2,522.00$ & 0.00 & $3,043.00$ \\
\hline Hematoma & 43.00 & 0.00 & 97.00 & 0.00 & 140.00 \\
\hline
\end{tabular}

${ }^{*}$ Costs in Canadian dollars. $\$ 1$ Cdn $=\$ 0.85$ US as of March 15, 2007. DIEP Deep inferior epigastric perforator flap; SIEA Superficial inferior epigastric artery flap 


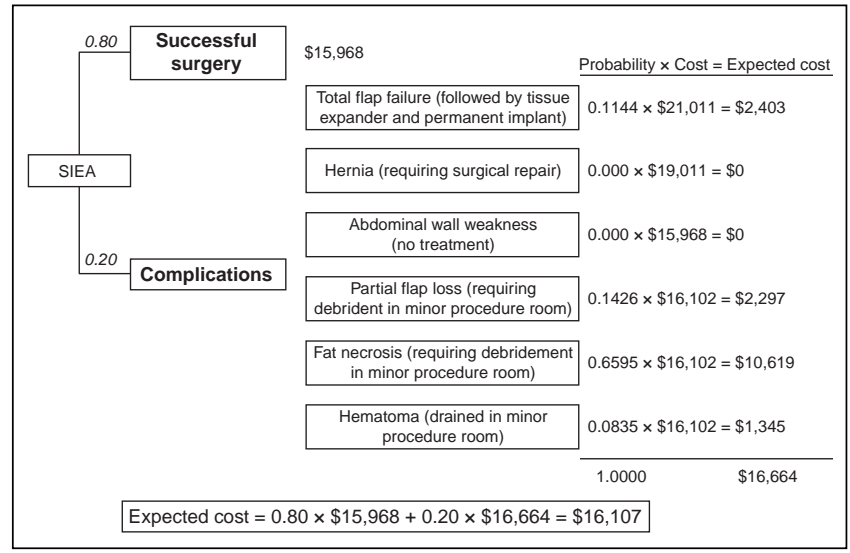

Figure 2) Superficial inferior epigastric artery (SIEA) flap model structure and results. Costs are in Canadian dollars $(\mathrm{CDN} \$ 1=$ US\$0.85 as of March 15, 2007)

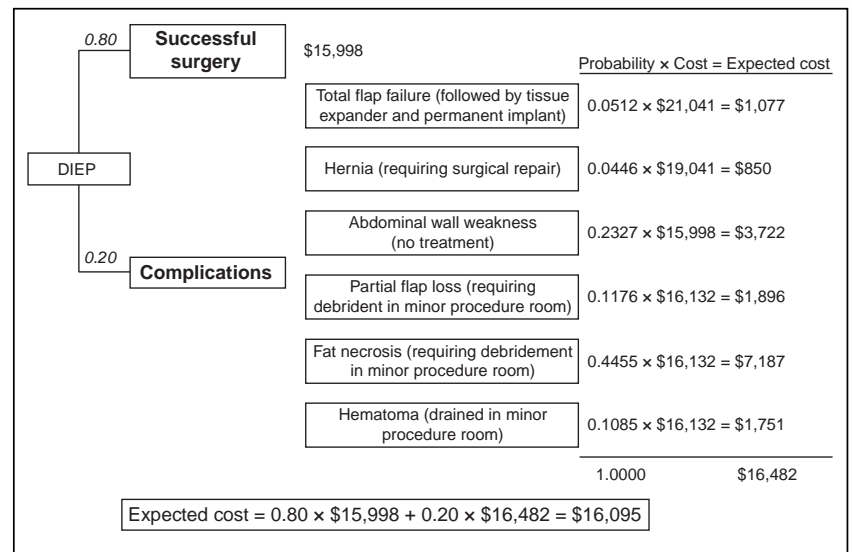

Figure 3) Deep inferior epigastric perforator (DIEP) flap model structure and results. Costs are in Canadian dollars (CDN\$1 = US\$0.85 as of March 15, 2007)

SIEA operative time was changed from $7.1 \mathrm{~h}$ to $6.7 \mathrm{~h}$ (the DIEP value), the SIEA became dominant. When the SIEA hernia rate was changed from $0.0 \%$ to $0.9 \%$ (the DIEP rate), the ICUR was \$197/QALY. When the SIEA total flap failure rate was changed from $2.3 \%$ to $1.0 \%$ (the DIEP rate), the SIEA ICUR became dominant. Finally, when the SIEA rate of abdominal wall weakness was changed from $0.0 \%$ to $4.7 \%$, the ICUR was $\$ 277 /$ QALY. Therefore, all sensitivity analysis scenarios are consistent with the cost-effectiveness of the SIEA.

\section{DISCUSSION}

Of the prevailing abdominal flaps, the SIEA flap should be the consummate flap for postmastectomy reconstruction because it leaves the rectus abdominis and its overlying fascia intact. Results from this cost-utility analysis identify the SIEA as a cost-effective procedure relative to the DIEP procedure. The ICUR of $\$ 77.40 / \mathrm{QALY}$ under the efficacy model is well below the threshold of $\$ 20,000 / \mathrm{QALY}$ that has been suggested in the literature. Although the ICUR is higher under the effectiveness model, it still remains well below the proposed $\$ 20,000 /$ QALY threshold. The results from the sensitivity analysis are consistent with the baseline model findings.
TABLE 5

Health state utilities and quality-adjusted life years (QALYs)

\begin{tabular}{lccc}
\hline Health state & Mean utility & Duration, years & QALY, years \\
\hline Successful reconstruction & 0.87 & 38.36 & 33.37 \\
Hematoma & 0.77 & 0.08 & 33.36 \\
Fat necrosis & 0.74 & 0.25 & 33.34 \\
Partial flap loss & 0.71 & 0.25 & 33.33 \\
Abdominal wall weakness & 0.71 & 38.36 & 27.24 \\
Hernia & 0.66 & 0.31 & 33.31 \\
Total flap failure & 0.61 & 38.36 & 23.40
\end{tabular}

Calculations assume a future life expectancy of 38.36 years. Adapted from reference 13

There has been much discussion in the literature regarding the interpretation and application of the ICUR metric. In particular, the quantitative thresholds proposed by Laupacis et al (27) in 1992 have been criticized for being arbitrary and outdated, although they remain in frequent use (55-57). For example, the National Institute for Health and Clinical Excellence of the British National Health Service uses $£ 20,000 /$ QALY as their ICUR threshold for acceptance of new technologies $(58,59)$.

Because utilities have not been reported in the breast reconstruction literature, we relied upon utilities derived from a survey of Canadian plastic surgeons. Obtaining utilities from patients (the preferred method) would have been a burdensome task given patients' unfamiliarity with the management and implications of postoperative complications. Ideally, utilities could be obtained from patients directly in a prospective study using validated instruments such as the Health Utilities Index Mark II/III, the EuroQol-5D and the Quality of WellBeing scale (60-66).

Our calculations were based on the future life expectancy for an average 45-year-old woman, according to life tables from Statistics Canada, but it is likely that the average life expectancy for breast cancer patients undergoing postmastectomy reconstruction is lower. We do not think that the difference would have an impact on our results.

We assumed that the health states are mutually exclusive and independent, but it is possible that one patient could have more than one outcome concurrently, for example both abdominal wall weakness and partial flap necrosis. We also assumed that all patients with total flap failure would return to the operating room for debridement of the necrotic flap and the insertion of tissue expanders, followed by permanent implants. It is possible that some patients would not choose any treatment, which would decrease the cost associated with this outcome, but the only impact of this on our results would be to further support the SIEA procedure as a cost-effective option.

Our calculations were based on inputs with values appropriate under the socialized Canadian health care system. Because we have described our methodology in sufficient detail, it should be possible for other investigators to recalculate costs and ICURs in their health care system.

Breast reconstruction has been moving toward the minimization of harvested muscle and fascia, yet most plastic surgeons do not currently use the SIEA flap. There are many factors that influence clinical decision making in microsurgery, including "clinical state, setting, microsurgical expertise, and 


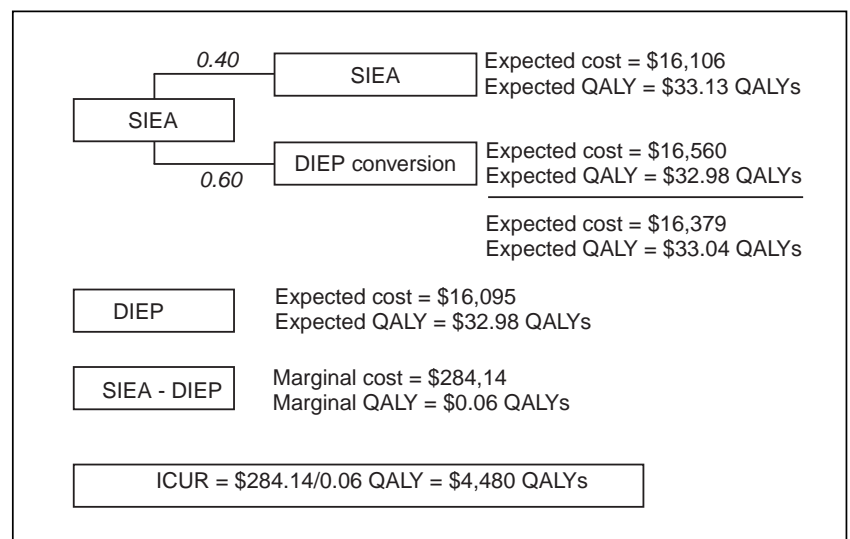

Figure 4) Effectiveness model results. Costs are in Canadian dollars (CDN\$1 = US\$0.85 as of March 15, 2007). DIEP Deep inferior epigastric perforator flap; ICUR Incremental cost-utility ratio; QALY Quality-adjusted life year; SIEA Superficial inferior epigastric artery flap

circumstances" (22). It is likely that the inherent uncertainty in whether the SIEA vessels will prove to be present and of suitable size and length if the SIEA flap is attempted, plays an important role in why the SIEA remains an infrequent flap choice. To resolve the controversy of whether the SIEA is 'truly' a cost-effective approach one needs to use evidence-based microsurgical principles (22).

The 'best evidence' we provided was based on secondary data. The data, in particular the probabilities of the various health states, were obtained from case series, which represents a lower level of evidence for clinical decision-making. Additionally, the QALYs were obtained using experts as proxies for patients (18). Because the incremental costs and

\section{REFERENCES}

1. Radovan IC. Breast reconstruction after mastectomy using the temporary expander. Plast Reconstr Surg 1982;69:195-208.

2. Olenius M, Jurell G. Breast reconstruction using tissue expansion. Scand J Plast Reconstr Surg Hand Surg 1992;26:83-90.

3. Agha-Mohammadi S, De La Cruz C, Hurwitz DJ. Breast reconstruction with alloplastic implants. J Surg Oncol 2006;94:471-8.

4. Hartrampf CR Jr. The transverse abdominal island flap for breast reconstruction: A 7-year experience. Clin Plast Surg 1988;15:703-16.

5. Grotting JC, Urist MM, Maddox WA, Vasconez LO. Conventional TRAM flap versus free microsurgical TRAM flap for immediate breast reconstruction. Plast Reconstr Surg 1989;83:828-41.

6. Chevray PM. Breast reconstruction with superficial inferior epigastric artery flaps: A prospective comparison with TRAM and DIEP flaps. Plast Reconstr Surg 2004;114:1077-83.

7. Allen RJ, Treece P. Deep inferior epigastric perforator flap for breast reconstruction. Ann Plast Surg 1994;32:32-8.

8. Blondeel PN, Boeckx WD. Refinements in free flap reconstruction: The free bilateral deep inferior epigastric perforator flap anastomosed to the internal mammary artery. Br J Plast Surg 1994;47:495-501.

9. Nahabedian MY, Tsangaris T, Momen B. Breast reconstruction with the DIEP flap or the muscle-sparing (MS-2) free TRAM flap: Is there a difference? Plast Reconstr Surg 2005;115:436-44.

10. Taylor GI, Daniel RK. The anatomy of several free flap donor sites. Plast Reconstr Surg 1975;56:243-53.

11. Grotting J. The free abdominoplasty flap for immediate breast reconstruction. Ann Plast Surg 1991;27:351-4.

12. Stern HS, Nahai F. The versatile superficial inferior epigastric artery free flap. Br J Plast Surg 1992;95:270-4.

13. Arnez ZM, Khan U, Pogorelec D, Planisek F. Rational selection of flaps from the abdomen in breast reconstruction to reduce donor site morbidity. Br J Plast Surg 1999;52:351-4.

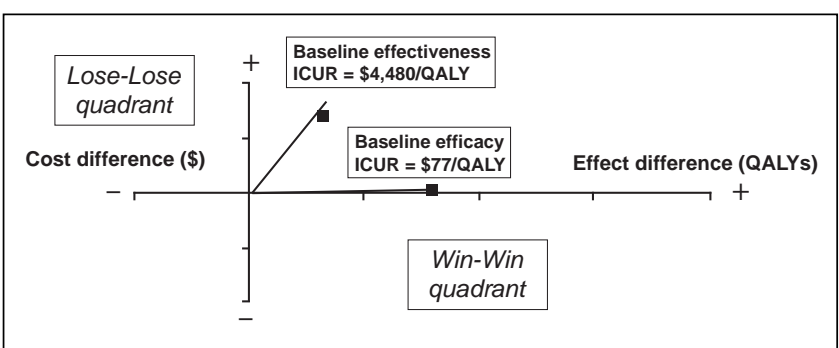

Figure 5) Baseline results on the cost-effectiveness plane. ICUR Incremental cost-utility ratio; QALY Quality-adjusted life year

benefits (QALYs) were marginal, it is possible that slight variation in cost and effectiveness would make the SIEA not costeffective (flip it to the 'lose-lose' quadrant).

Future investigators in centres with large volumes of breast reconstruction cases need to perform a parallel, randomized, controlled trial comparing the SIEA and DIEP, and simultaneously capturing the true costs (both direct and indirect) and effectiveness while taking into account the SIEA conversion rates in an intent-to-treat analysis.

ACKNOWLEDGEMENTS: We acknowledge the editorial assistance of Leslie McKnight MSc and Paula McKay BSc

DISCLAIMER: No funding was received for the preparation of this manuscript.

This study was presented at the Groupe pour l'Avancement de la Microchirugie Canada (GAM) Meeting, Banff, Alberta, May 2007, and at the IV Congress of the World Society of Microsurgeons, Athens, Greece, June 2007.

14. Serafin D, ed. Atlas of Microsurgical Composite Tissue Transplantation, Durham: WB Saunders, 1996.

15. Tachi M, Yamada A. Choice of flaps for breast reconstruction. Int J Clin Oncol 2005;10:289-97.

16. Craigie JE, Allen RJ, DellaCroce FJ, Sullivan SK. Autogenous breast reconstruction with the deep inferior epigastric perforator flap. Clin Plastic Surg 2003;30:359-69.

17. Thoma A, Khuthaila D, Rockwell G, Veltri K. Cost-utility analysis comparing free and pedicled TRAM flap for breast reconstruction. Microsurgery 2003;23:287-95.

18. Thoma A, Veltri K, Khuthaila D, Rockwell G, Duku E. Comparison of the deep inferior epigastric perforator flap and free transverse rectus abdominis myocutaneous flap in postmastectomy reconstruction: A cost-effectiveness analysis. Plast Reconstr Surg 2004;113:1650-61.

19. Cheng MH, Lin JY, Ulusal BG, Wei FC. Comparisons of resource costs and success rates between immediate and delayed breast reconstruction using DIEP or SIEA flaps under a well-controlled clinical trial. Plast Reconstr Surg 2006;117:2139-42.

20. Thoma A, Sprague S, Tandan V. Users' guide to the surgical literature: How to use an article on economic analysis. Can J Surg 2001;44:347-54

21. Russell LB, Gold MR, Siegel JE, Daniels N, Weinstein MC. The role of cost-effectiveness analysis in health and medicine: Panel on cost-effectiveness in health and medicine. JAMA 1996;276:1172-7.

22. Thoma A, Sprague S. Methodological issues in the comparison of microsurgical flaps/techniques in head and neck reconstruction. Clin Plastic Surg 2005;32:347-59.

23. Chevray P. Breast reconstruction with superficial inferior epigastric artery flaps: A prospective comparison with TRAM and DIEP flaps. Plast Reconstr Surg 2004;114:1077-83.

24. Rizzuto RP, Allen RJ. Reconstruction of a partial mastectomy defect with the superficial inferior epigastric artery (SIEA) flap. J Reconstr Microsurg 2004;20:441-5. 
25. Ontario Ministry of Health. Ontario Ministry of Health Schedule of Benefits: Physician Services Under the Health Insurance Act (July 1, 2006). Hamilton, Ontario, Canada: Ministry of Health and Long-Term Care, July 2006.

26. Drummond MF, O'Brien BJ, Stoddart GL, Torrance GW. Methods for the Economic Evaluation of Health Care Programmes, 2nd edn. New York, Oxford: Oxford University Press, 1997.

27. Laupacis A, Feeny D, Detsky AS, Tugwell PX. How attractive does a technology have to be to warrant adoption and utilization? Tentative guidelines for using clinical and economic evaluations. CMAJ 1992;146:473-81.

28. Vermeulen P, Fabre G, Vandevoort, M. The superficial inferior epigastric artery flap for breast reconstruction. Results and complications in 43 cases. Meeting of the American Society for Reconstructive Microsurgery, January 15-18, 2005. (Abst)

29. Craigie JE, Allen RJ, Heitland AS. Autogenous breast reconstruction with the superficial inferior epigastric artery flap. Meeting of the American Society for Reconstructive Microsurgery, January 11-14, 2003. (Abst)

30. Vega SJ, Bossert RP, Serletti JM. Improving outcomes in bilateral breast reconstruction using autogenous tissue. Ann Plast Surg 2006;56:487-90.

31. Bajaj AK, Chevray PM, Chang DW. Comparison of donor-site complications and functional outcomes in free muscle-sparing TRAM flap and free DIEP flap breast reconstruction. Plast Reconstr Surg 2006;117:737-46.

32. Benditte-Klepetko H, Sommer O, Steinbach R, Czembirek H, Deutinger M. Clinical and ultrasound evaluation of donor site morbidity after tram-flap for breast reconstruction. Microsurgery 2004;24:174-81.

33. Blondeel N, Vanderstraeten GG, Monstrey SJ, et al. The donor site morbidity of free DIEP flaps and free TRAM flaps for breast reconstruction. Br J Plast Surg 1997;50:322-30.

34. Blondeel PN. One hundred free DIEP flap breast reconstructions: A personal experience. Br J Plast Surg 1999;52:104-11.

35. Blondeel PN, Arnstein M, Verstraete K, et al. Venous congestion and blood flow in free transverse rectus abdominis myocutaneous and deep inferior epigastric perforator flaps. Plast Reconstr Surg 2000;106:1295-9.

36. Futter CM, Webster MH, Hagen S, Mitchell SL. A retrospective comparison of abdominal muscle strength following breast reconstruction with a free TRAM or DIEP flap. Br J Plast Surg 2000;53:578-83.

37. Garvey PB, Buchel EW, Pockaj BA, Gray RJ, Samson TD. The deep inferior epigastric perforator flap for breast reconstruction in overweight and obese patients. Plast Reconstr Surg 2005;115:447-57.

38. Gill PS, Hunt JP, Guerra AB, et al. A 10-year retrospective review of 758 DIEP flaps for breast reconstruction. Plast Reconstr Surg 2004;113:1153-60.

39. Guerra AB, Metzinger SE, Bidros RS, et al. Bilateral breast reconstruction with the deep inferior epigastric perforator (DIEP) flap: An experience with 280 flaps. Ann Plast Surg 2004;52:246-52.

40. Guzzetti T, Morris R, Webster MH. Early experience with the deep inferior epigastric perforator flap in breast reconstruction. Eur J Plast Surg 1997;20:205-8.

41. Hamdi M, Weiler-Mithoff EM, Webster MH. Deep inferior epigastric perforator flap in breast reconstruction: Experience with the first 50 flaps. Plast Reconstr Surg 1999;103:86-95.

42. Hamdi M, Blondeel P, Van Landuyt K, Tondu T, Monstrey S. Bilateral autogenous breast reconstruction using perforator free flaps: A single center's experience. Plast Reconstr Surg 2004:114:83-9.

43. Keller $A$. The deep inferior epigastric perforator free flap for breast reconstruction. Ann Plast Surg 2001;46:474-9.

44. Kroll SS. Fat necrosis in free transverse rectus abdominis myocutaneous and deep inferior epigastric perforator flaps. Plast Reconstr Surg 2000;106:576-83.
45. Lundberg J, Mark H. Avoidance of complications after the use of deep inferior epigastric perforator flaps for reconstruction of the breast. Scand J Plast Reconstr Surg Hand Surg 2006;40:79-81.

46. Misra A, Chester D, Park A. A comparison of postoperative pain between DIEP and extended latissimus dorsi flaps in breast reconstruction. Plast Reconstr Surg 2006;117:1108-12.

47. Munhoz AM, Ishida LH, Montag E, et al. Perforator flap breast reconstruction using internal mammary perforator branches as a recipient site: An anatomical and clinical analysis. Plast Reconstr Surg 2004;114:62-8.

48. Munhoz AM, Sturtz G, Montag E, et al. Clinical outcome of abdominal wall after DIEP flap harvesting and immediate application of abdominoplasty techniques. Plast Reconstr Surg 2005;116:1881-93.

49. Nahabedian MY, Momen B, Galdino G, Manson PN. Breast reconstruction with the free TRAM or DIEP flap: Patient selection, choice of flap, and outcome. Plast Reconstr Surg 2002;110:466-75

50. Nahabedian MY, Dooley W, Singh N, Manson PN. Contour abnormalities of the abdomen after breast reconstruction with abdominal flaps: The role of muscle preservation. Plast Reconstr Surg 2002;109:91-101

51. Nahabedian MY, Momen B, Manson PN. Factors associated with anastomotic failure after microvascular reconstruction of the breast. Plast Reconstr Surg 2004;114:74-82.

52. Nahabedian MY, Momen B. Lower abdominal bulge after deep inferior epigastric perforator flap (DIEP) breast reconstruction. Ann Plast Surg 2005;54:124-9.

53. Vesely J, Stupka I, Drazan L, Holusa P, Licata P, Corradini B. DIEP flap breast reconstruction - new experience. Acta Chir Plast 2001:43:3-6.

54. Statistics Canada. Complete life table, Canada, 2000 to 2002: females. <www.statcan.ca/english/freepub/84-537.

XIE/tables/pdftables/caf.pdf $>$. (Version current at April 22, 2008).

55. Asim O, Petrou S. Valuing a QALY: Review of current controversies. Expert Rev Pharmacoeconomics Outcomes Res 2005;5:667-9.

56. McGregor M, Caro JJ. QALYs: Are they helpful to decision makers? Pharmacoeconomics 2006;24:947-52.

57. Vijan S. Should we abandon QALYs as a resource allocation tool? Pharmacoeconomics 2006;24:953-4.

58. Pearson SD, Rawlins MD. Quality, innovation, and value for money: NICE and the British National Health Service. JAMA 2005;294:2618-22.

59. Buxton MJ. Economic evaluation and decision making in the UK. Pharmacoeconomics 2006;24:1133-42.

60. Thoma A, Veltri K, Haines T, Goldsmith C, O'Brien B, Quartly C. A methodological guide to performing a cost-utility study comparing surgical techniques. Can J Plast Surg 2004;12:179-87.

61. Furlong WJ, Feeny DH, Torrance GW, Barr RD. The Health Utilities Index (HUI) system for assessing health-related quality of life in clinical studies. Ann Med 2001;33:375-84.

62. Feeny D, Furlong W, Torrance GW, et al. Multiattribute and singleattribute utility functions for the health utilities index mark 3 system. Med Care 2002;40:113-28.

63. Horsman J, Furlong B, Feeny D, Torrance G. The Health Utilities Index (HUI): concepts, measurement properties, and applications. Health Qual Life Outcomes. 2003 Oct 16;1:54.

64. Brooks R. EuroQol: The current state of play. Health Policy 1996;27:53-72

65. Rabin R, de Charro F. EQ-5D: A measure of health status from the EuroQol Group. Ann Med 2001;33:337-43.

66. Kaplan RM, Anderson JP. A general health policy model: Update and applications. Health Serv Res 1988;23:203-35. 